DOI: https://doi.org/10.24867/03AM05Sremacki

\title{
ISPITIVANJE ALTERNATIVNOG TURBINSKOG MERILA PROTOKA GORIVA PRI TOČENJU GORIVA NA BENZINSKIM PUMPAMA
}

\author{
FUEL TURBINE FLOW METER TESTING
}

\author{
Branka Sremački, Fakultet tehničkih nauka, Novi Sad
}

\section{Oblast - MAŠINSTVO}

Kratak sadržaj - U ovom radu data su teorijska $i$ laboratorijska rešenja kalibracije turbinskog merila protoka goriva. Objašnjeni su i uticajni faktori procesa kalibracije. Izvršeno je ispitivanje sistema za merenje protoka. Objašnjen je postupak merenja. Date su karakteristike korišćene opreme i prikazani su rezultati ispitivanja.

Ključne reči: Turbinska merila, Kalibracija

\begin{abstract}
In this paper, theoretical and laboratory solutions of the calibration of the turbinefuel flow meter are given. The influence factors of the calibration process are also explained. The flow measurement systems was tasted. The measurement procedure is explained. Characteristics of used equipment are given and the test results are shown.
\end{abstract}

Key words: turbinefuel flow meter, calibration process

\section{UVOD}

Zapreminski, ili maseni, protok fluida predstavlja najzahtevniju karakteristiku fluida $\mathrm{u}$ odnosu na mogućnost merenja. Turbinska merila se široko primenjuju zbog sposobnosti da odgovore specijalnim zahtevima u svakoj konkretnoj primeni. Popularnosti ovih merila najviše doprinose njihove metrološke karakteristike koje ih čine superiornim u odnosu na druga merila. Turbinska merila protoka široko se koriste za merenje protoka tečnosti. Ponovljivost je najvažnije svojstvo merila. Merila se moraju kalibrisati i koriste se za različite fluide. Kalibracija je poređenje standarda i očitanih rezultata koje daje uređaj. Pogodniji oblik kalibracionih podataka zove se univerzalna kriva viskoznosti.

\section{ZADATAK RADA}

Zadatak rada je ispitivanje pištolja za točenje goriva. Potrebno je odrediti tačnosti merenja pri njegovom korišćenju. Tome prethodi teorijski opis kalibracije turbinskih merila $\mathrm{i}$ predstavljanje uticajnih faktora. Takođe treba izvršiti ispitivanje uticaja položaja pištolja za točenje goriva u samom uvodniku na tačnost merenja i utvrditi optimalnu visinu uvodnika i ugao konusnih umetaka ispred turbinskog kola za pištolj za točenje goriva.

\section{NAPOMENA:}

Ovaj rad proistekao je iz master rada čiji mentor je bila dr Maša Bukurov, red. prof.

\section{OPŠTE O MERENJU PROTOKA FLUIDA I MERILA}

Merenje protoka fluida se ostvaruje direktnom metodom pomoću različitih tipova merila kod kojih se osnovni indikator postavlja neposredno u fluidnu struju. Da bi se moglo vršiti mernje protoka, nezavisno od tipa merila, neophodno je poznavati zavisnost između protoka $Q$ i izlaznog signala merila $x$, koji je obično dat kao: frekvencija električnih impulsa, električni napon, jačina električne struje, otklon kazaljke na skali, itd. Matematički izraz [1]

$$
Q=f(x)
$$

naziva se funkcija transformacije merila, a određuje se kalibracijom merila.

U opštem slučaju, za svako merilo su važne sledeće osobine: ponovljivost, pouzdnost i tačnost $i$ to po napisanom redosledu prioriteta. Sama tačnost je od sekundarnog značaja. Temperatura utiče na fizička svojstva radnog fluida i naročito na njegovu viskoznost. Slično kao i temperatura radnog fluida, visok strujni pritisak utiče na promenu dimenzija kućišta merila, pa prema tome i merne komore kada ona sa kućištem predstavlja jedinstvenu celinu.

Turbinsko merilo zahteva linearnu vezu između brzine merila i protoka, u širokom spektru protoka i viskoznosti merenih tečnosti. $U$ dozirnim tečnostima visokog viskoziteta uslovi protoka kroz turbinsko merilo, mogu biti turbulentni, prelazni ili čak i laminarni. Shodno tome, uticaj viskoznosti na preciznost merila postaje veoma važan [2]. Nijedno drugo gledište u problematici turbinskih merila nije izazvalo veće interesovanje i nesuglasice od njihovog ponašanja $u$ viskoznim tečnostima.

\section{KALIBRACIJA TURBINSKIH MERILA}

Kalibracija nije apsolutna operacija. To je poređenje između mernog instrumenta, uređaja koji se testira ili merila protoka, i standarda. Kroz ovo poređenje, uspostavlja se odnos između količine izmerne uređajem u okviru testa, i merenja iste količine izvedene iz standarda. $\mathrm{Na}$ taj način dobijaju se očekivanja kako će uređaj obavljati svoju funkciju, tj. način na koji će se upotrbljavati. Postupak kalibracije izvodi se po određenoj proceduri i uz korišćenje izabranih metoda [3]. 
Merenje protoka tečnosti zavisi od uspostavljanja opsega merenog protoka i niza uticajnih faktora. Količina tečnosti može se izraziti preko zapremine ili mase. Merenje može biti izraženo količinski ili kao količina po jedinici vremena. Količina merena standardom može se razlikovati od količine koja je prošla kroz uređaj testiranja usled promena u obimu ili čak mase između merila i standarda. Merenje protoka fluida je dinamičan proces i svi merni uređaji su pod uticajem načina i uslova korišćenja. Protočni uređaji su pogođeni od strane temperature, viskoznosti, profila protoka. Oni takođe zavise i od strane spoljašnje sredine, vibracije, stresa i temperature itd. Različiti uređaji su pogođeni na različite načine. Slični standardni će biti podložni istim uticajima.

Da bi se dobilo proverljivo merenje, očekuje se, da bi pri ponovljenom merenju trebalo da se dobije isti rezultat. $U$ praksi, merenje se ponavlja samo u određenom opsegu tokom kratkog vremena i (verovatno) širem opsegu tokom dugog vremenskog perioda ili u različitim okolnostima. Obično se očekuje da kalibracija treba da da neke indikacije o ponovljivosti instrumenta.

Iako može izgledati očigledno, rezolucija uređaja mora biti adekvatna da omogući kalibraciji odgovarajuću potrebnu nesigurnost. Da bi se to postiglo, standard mora biti u stanju da izmeri dovoljno tečnosti da odgovara rezoluciji uređaja.

Sva merila protoka intereaguju na neki način sa tečnim fluidom. Na prirodu ove interakcije utiču svojstva tečnosti ili brzine fluida koja prolazi kroz uređaj. Promene u ovoj interakciji menjaju sposobnost uređaja da daje tačnu predstavu o količini. Veličina greške je različita za različite tipove merila i tečnosti. Iz tog razloga je poželjno da se kalibriracija vrši koristeći iste tečnosti i cevovode u okviru kojeg će merila normalno funkcionisati.

Greška merenja je razlika između izmerene vrednosti i prave vrednosti izmerene veličine. Merna nesigurnost je parametar povezan sa rezultatom merenja koji karakteriše disperziju vrednosti koje bi se mogle dodeliti merenoj veličini [4]. Da bi se prikazali rezultati kalibracije, potrebno je da priroda podataka koji proizilaze iz merila budu razumljiva. Protočna merila mogu pokazivati protok ili količinu u izvesnom broju na različite načine. Dobijeni podaci o merenju mogu biti prikazani mehaničkim ispisom ili na elektronskom displeju na kome se navodi količina ili protok, a moguć je i elektronski izlaz na bazi impulsa, frekvencije ili struja (mA).

Izlaz ili ekran se zasniva na merenjima (npr. frekvencija, protok, diferencijalni pritisak ili $\mathrm{mA}$ ). Merenja obično, ponekad, variraju tokom merenja. Normalno je da se uzme prosek, srednja vrednost čitanja, svih dobijenih parametara tokom kalibracije.

\section{UTICAJNI PARAMETRI}

Dinamička viskoznost je karakteristika tečnosti, koja predstvlja otpor strujanju. Što je veća numerička vrednost dinamičke viskoznosti tečnosti, to je veći otpor tečenju.
Viskoznost tečnosti je jako zavisna od temperature. Povećanje temperature će izazvati smanjenje viskoznosti. Iz tog razloga, temperatura može značajno da utiče na performanse merila protoka.

Dinamička viskoznost njutnovskih fluida podeljena sa gustinom fluida naziva se kinematska viskoznost [5].

$v=\frac{\eta}{\rho}\left[\frac{\mathrm{m}^{2}}{\mathrm{~s}}\right]$

Viskoznost se najčešće meri viskozimetrom sa rotirajućim cilindrom ili kapilarnim viskozimetrom. Viskozimetrom sa rotirajućim cilindrom mere se tangencijalne sile koje deluju na fluid i na taj način se određuje dinamička viskoznost. Dinamička viskoznost obično se određuje u centipoasima $[\mathrm{cP}] \mathrm{tj}$. [mPa.s]. Da bi se dobila kinematska viskoznost mora se prethodno odrediti gustina fluida. Kinematska viskoznost se izražava u centistoksima [cSt] tj. $\left[\mathrm{mm}^{2} / \mathrm{s}\right]$

Dinamička viskoznost fluida veoma je zavisna od temperature. Sa porastom temperature, viskoznost tečnosti opada, a viskoznosti gasa se povećava. Uticaj pritiska na dinamičku viskoznosti obično se zanemaruje, što je prihvatljivo na niskim pritiscima. Međutim, za pritiske preko $7 \mathrm{MPa}$, dinamička viskoznost tečnosti može značajno da zavisi od pritiska. Generalno, povećanje pritiska će povećati viskoznost tečnosti [6].

Kinematička viskoznost je odnos dinamičke viskoznosti i gustine. Dakle, ako se gustina menja sa temperaturom ili pritiskom, i kinematska viskoznost će se promeniti. Za gasove, kinematska viskoznost snažno zavisi od pritiska. Kinematska viskoznost je ključni parametar tečnosti koji utiče na performanse turbinskog merila [7].

Strujanje fluida se karakteriše kao laminarni ili turbulentni strujni režim. Kod laminarnog strujanja radi se o kretanju tečnosti u slojevima, glatko klizanje jednog sloja preko drugog. Nema mešanja tečnosti iz sloja u sloj. Dobijeni profil brzina je paraboličnog oblika.

U turbulentnoj struji ne postoje odvojeni slojevi. Količina kretanja fluida prevladava viskozne sile i javlja se intenzivno i kontinualno mešanje fluida duž strujanja.

Kada viskozna tečnost struji preko čvrste površine, sila koja deluje na površinu je u tangencijalnom pravcu. U stvari, tečnost pokušava da povuče čvrstu površinu za sobom. Veličina ove sile zavisi od viskoznosti i brzine fluida.

Eksperimentalno izmerena sila otpora trenja $\mathrm{F}$ obično se prikazuje kao $C_{D}$ u funkciji od Re, gde je $C_{D}$ koeficijent otpora definisan kao:

$C_{D}=\frac{F}{\frac{1}{2} \rho v^{2} A}$

gde su: 
$v$ - brzina fluida

$A$ - okvašena površina.

Dijagram zavisnosti $C_{D}$ od $R e$ izgleda kao na slici 1 . koeficijent otpora brzo se smanjuje sa povećanjem Rejnoldsovog broja pri laminarnom strujanju, raste naglo u prelaznoj oblasti, zatim se ustaljuje i na kraju polako smanjuje u turbulentnoj oblasti.

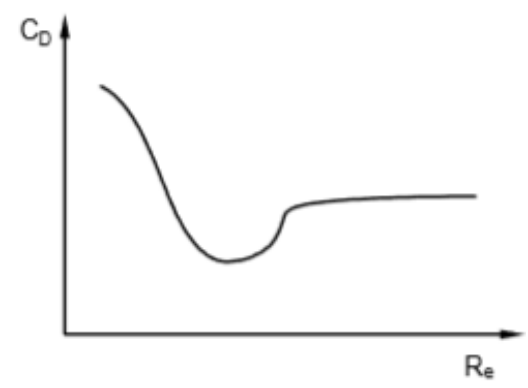

Slika 1. Zavisnost $C_{D}$ od Re

Kalibracija turbinskog merila protoka sastoji se od registrovanja izlazne frekvencije merila pri određenim veličinama protoka određenog od strane referentnog merila protoka. Rezultat je linearna kriva kao što je prikazano na slici 2. Međutim, ova kriva važi samo za fluide sa približno jednakom kinematskom viskoznošću tečnosti koja se koristi za kalibraciju.

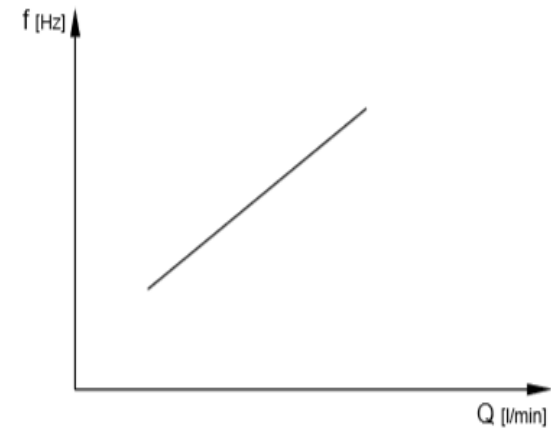

Slika 2. Kalibraciona kriva

Pogodniji oblik kalibracionih podataka zove se univerzalna kriva viskoznosti. Ovo je polu-logaritamska kriva osetljivosti merila, u funkciji odnosa izlazne frekvencije i kinematske viskoznost, slika 3. Osetljivost merila poznatija je kao faktor $K$, i predstavlja broj impulsa merila koje proizvodi svaki litar tečnosti koja protiče kroz njega. Ona je izvedena iz podataka kalibracije na sledeći način: $K=f \cdot 60 / Q$.

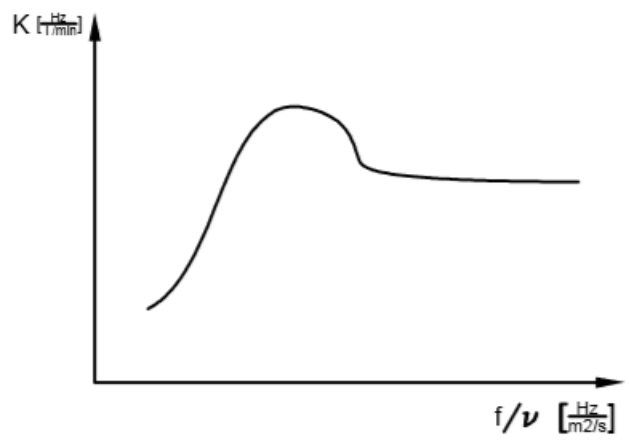

Slika 3. Osetljivost merila $K$ u funkciji odnosa $\mathrm{f} / v$

\section{METODOLOGIJA ISPITIVANJA}

Turbinsko merilo protoka je predmet ispitivanja. Ispitivanje je obavljeno u Laboratoriji za mehaniku fluida Fakulteta tehničkih nauka. Rađena su dva nezavisna niza merenja. Prvi niz merenja radilo se za pet različitih protoka. Za svaki protok izvršeno je pet merenja, pri istim uslovima. Prvi niz merenja služi za određivanje kalibracione krive i matematičkog modela. Drugi niz merenja koristi se za proveru dobijenog matematičkog modela. Pri tome je vršeno merenje za četiri različita protoka koji se nalazi između vrednosti protoka u prvom nizu merenja. Za svaki protok izvršeno je pet merenja pri istim uslovima. Drugim nizom merenja ispitana je tačnost uređaja. Rezultati dobijeni korišćenjem matematičkog modela upoređene su sa vrednostima protoka dobijenim masenim, odnosno zapreminskom metodom (merenje pomoću vage). Postrojenje za ispitivanje prikazano je na slici 4.

Vazduh se iz kompresorske stanice (slika 4) dovodi preko dovodnog voda (1) i finog regulatora pritiska (2) u glavni rezervoar (3) pri čemu je ventil (10) otvoren. Na dovodnom vodu se nalazi grub regulator pritiska i primpremna grupa. Da ne bi toliko oscilovao pritisak u sistemu postavlja se taj fini regulator pritiska. Fini regulator ima mnogo bolju regulacionu grupu i zahvaljujući njemu se održava znatno ujednačeniji pritisak unutar glavnog rezervoara. Kada se postigne pritisak koji se očitava na manometru (15), koji odgovara željenom protoku, kreće sa sa merenjima. To je jedan kontrolni manometar koji ima dobru rezoluciju očitavanja.

Fluid se pri otvorenom ventilu (11) potiskuje kroz potisni vod i pištolj za točenje goriva (5) na kraju voda (4). Pomoću tog pištolja se startuje i prekida merenje i protok. U cilju simulacije realnih uslova korišćene su izmenljive čaure za usmeravanje goriva koje se montiraju na ulazu $u$ ispitivano turbinsko merilo protoka (16). Fluid nakon merila protoka (16) ulazi u prihvatni rezervoar (6) koji se nalazi na vagi (7). Vagom (7) se određuje masa fluida koji istekne za određen vremenski period. Vaga je apsolutno merilo i potrebno je preračunati maseni protok $u$ zapreminski. Posle svakog procesa merenja, kada se gorivo vrati nazad, potrebno je tarirati vagu na 0 . Pomoću akvizicije (17) dobija se promena impulsa u sekundi ispitivanog merila (16). Akvizicija je povezana i sa kompjuterom, da se ne bi pravila velika greška u merenju. Zbog toga je tu postavljen jedan mikro-prekidač, koji, kada se pištolj startuje, on pošalje signal i startuje vreme. Kada se pištolj otpusti on zaustavlja ovaj prekidač i zaustavi se i vreme.

Nakon završetka merenja, zatvara se ventil (10), a zatim se preko odušnog voda (9) i ventila (12) pritisak u rezervoaru izjednačava sa atmosferskim. Odušni vod nam je veza sa atmosferom. Fluid se iz prihvatnog rezervoara (6) pretače preko povratnog voda sa pumpom (8), pri čemu su ventili (13) i (14) otvoreni, u glavni rezervoar (3). 


\section{KORIŠĆENA OPREMA}

Tokom ispitivanja korišćena je sledeća oprema:

- Pripremna grupa MACP401-15A-C-T15-BSP,

- precizni regulator pritiska MAIR100-6A-8K-C$\mathrm{G}$,

- vaga Shollex tip SHYH,

- pištolj za točenje goriva,

- centrifugalna pumpa „Pedrollo“ model SPm $132 \mathrm{~A}$,

- glavni rezervoar,

- pomocni rezervoar,

- uvodnik,

- umeci,

- ispitivano turbinsko merilo.

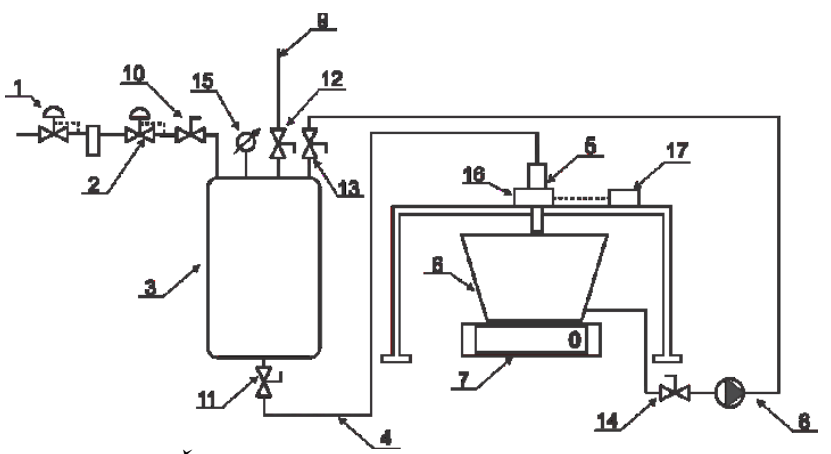

Slika 4. Šematski prikaz postrojenja za ispitivanje

\section{REZULTATI ISPITIVANJA}

Turbinsko merilo kalibrisano je uz pomoć pištolja za gorivo, u skladu sa uslovima koji su najpribližniji eksplatacionim.

Kalibracioni model je prikazan na slici 5.

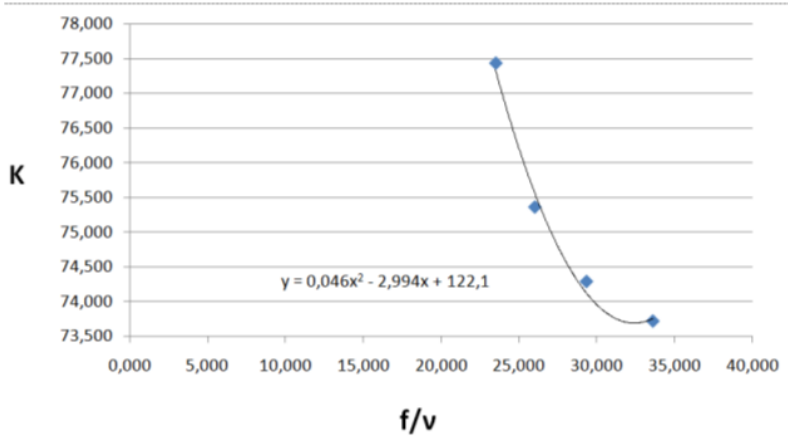

Slika 5. Kalibraciona kriva turbinskog merila

Rezultati provere su prikazani u tabeli 1 , gde se vidi da je tačnost merenja do $\pm 1,6 \%$.

Tabela 1. Rezultati ispitivanja tačnosti turbinskog merila

\begin{tabular}{|c|c|c|c|c|}
\hline Imp/s & $\boldsymbol{m}[\mathbf{k g}]$ & $\boldsymbol{Q}[\mathbf{L} / \mathbf{m i n}]$ & $\begin{array}{c}\boldsymbol{Q}_{\boldsymbol{m}} \\
{[\mathbf{L} / \mathbf{m i n}]}\end{array}$ & $\boldsymbol{\varepsilon}[\mathbf{\%}]$ \\
\hline 86,04 & 56,9 & 68,55 & 67,46 & 1,6 \\
\hline 104,40 & 69,38 & 83,59 & 84,68 & 1,3 \\
\hline 115,04 & 77,92 & 93,89 & 93,68 & 0,22 \\
\hline
\end{tabular}

\section{ZAKLJUČAK}

Nakon kalibracije i provere pištolja utvrđeno je da je tačnost merenja u granicama $\pm 2 \%$.

Utvrđeno je da je neophodno da pištolj za točenje goriva bude što saosniji sa uvodnikom u merilo protoka. Narušavanje saosnosti značajno utiče na grešku merenja. Ako se ispuni uslov saosnosti, dubina uvođenja pištolja u uvodnik nije od značajnog uticaja na tačnost merenja.

Određeno je da visina uvodnika bude $80 \mathrm{~mm}$ kako bi se sprečio kontakt pištolja za točenje goriva i radnog kola turbinskog merila. Izmenljivi konusni umeci nisu imali veći uticaj na tačnost merenja kod pištolja za točenje goriva. Bez obzira na tip umetaka tačnost merenja kretala se u granicama od $\pm 2 \%$.

\section{LITERATURA}

[1] Cvijanović S. Petar, Turbinska merila zapremine tečnosti, monografija.

[2] W. F. Z. LEE Chief Research Analyst, Central Research and Development Laboratory, Rockwell Manufacturing Company, Pittsburgh, Pa, A Study if Viscosity Effect anil Its Compensation on TurbineType Flowmeters.

[3] www.am.unze.ba/mt/2014/Begic.ppt

[4] http://www.super-lab.com/fajlovi-upload/brosurametrolab-2018.pdf

[5] Bukurov, M., Mehanika fluida, knjiga prva, FTN izdavaštvo, Novi Sad, 2013.

[6] Rubin, M., Miller, R.W., and Fox, W.G. Driving Torques in a Theoretical Model of a Turbine Meter, Transactions of the ASME. Journal of Basic Engineering, Paper Number 64 - WA/FM-2, 1965.

[7] https://ftimeters.com/wpcontent/uploads/2017/.../Universal-Calibrations-FTSeries.pdf viskoznost.

\section{Kratka biografija:}

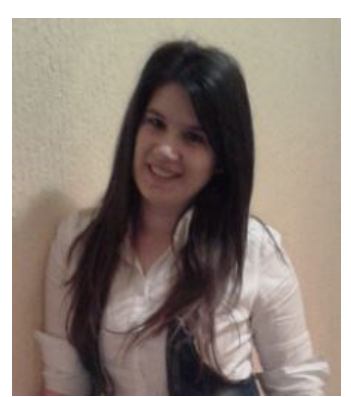

Branka Sremački rođena je u Subotici 1991. god. Diplomskimaster rad na Fakultetu tehničkih nauka iz oblasti Mašinstva Gasna i naftna tehnika odbranila je 2016.god. 